\title{
El ensayo de interpretación del ser nacional: su problemática y el caso de Nosotros de Luis López de Mesa ${ }^{1}$
}

\section{Resumen}

Este texto se divide en dos partes: la primera aborda el ensayo de interpretación del ser nacional, las voces que lo han desarrollado en América Latina y cuestiona la falta de reconocimiento de este género en Colombia. La segunda considera a Luis López de Mesa: partiendo de su obra De cómo se ha formado la nación colombiana, analiza las estrategias literarias de las que éste se vale en Nosotros para mostrar la identidad antioqueña como resultado de una debacle moral. En el desarrollo del análisis se encuentra que la industrialización de Antioquia hizo mundanos su valores humanos.

Palabras claves ensayo, ensayo de interpretación, literatura colombiana, Luis López de Mesa, Nosotros.

\begin{abstract}
This text is divided into two parts: the first one talks about the essay of interepretation of the national being, the voices that have developed it in Latin America and questions the lack of recognition of this genre in Colombia. The second part considers Luis López de Mesa: taking into account his work De Cómo se ha Formado la Nación Colombiana, analyzes the literary strategies applied by him in Nosotros to show the Antioquian identity as the result of a moral debacle. The conclusion is that Antioquia's industrialization turned its human values into shallow values.

Keywords essay, essay of interpretation, Colombian literature, Luis Lopez de Mesa, Nosotros.

${ }^{1}$ Este texto fue desarrollado en colaboración con la Universidad Eafit, Colombia, dentro del proyecto "La representación del ser nacional y continental en el ensayo literario colombiano de los siglos XIX y XX".
\end{abstract}


Con marcada diferencia, el único género literario del que se puede predicar una génesis en un momento y lugar determinados, es del ensayo. Inaugurado en las postrimerías del S. XVI en Francia por Michel de Montaigne, el texto ensayístico propone una introspección irreverente a las formas, comprometida con la estética mas no con la técnica y siempre predispuesta a la crítica. Aun así, en su devenir histórico, el ensayo nunca ha tenido más tema que el ensayista mismo y su forma de ver el mundo; su condición de texto "en primera persona" le permite al autor oscilar sin problemas entre aquellos fenómenos con los que se encuentra de acuerdo y aquellos que no tolera sin necesidad de revelar su propia postura. Como lo expresa Giraldo "El ensayo consuma un gesto rapsódico con el que se afirman dos individualidades: la de lo dicho y la del que dice. La apariencia de confesión es solo el efecto de pensamientos expresados siempre en clave de vivencia" (242); luego, es posible decir que la littérarité del texto ensayístico no se encuentra en la elocuencia con la que desarrolla temáticas disímiles, sino en la divergencia de perspectivas que puede presentar el autor a su lector, pudiendo llegar hasta la contradicción, la duplicación o, incluso, al autoplagio. Este personaje, que es el autor pero al propio tiempo no lo es, es quien marca la pauta para la recepción de la obra, y su falta de compromiso frente a lo que escribe es factor definitorio de su relación con el lector: su mirada, esa que refleja en el escrito, no es la de un narrador omnisciente, ni la de un poeta contemplativo, es la de un ser tan terrenal como quien pretende que lo lea, con la condición adicional de que ese eventual receptor no debe sentirse sermoneado o manipulado pues, aunque el ensayo puede usar la argumentación como mecanismo de construcción textual, su fin último se resume en la satisfacción personal de quien escribe y no en la persuasión o seducción de quien lee.

Que el ensayista hable de igual a igual con el lector no significa que dialogue con él. En el mejor de los casos el escritor lo interpelará para generar algún efecto en la recepción, mas tal actitud no puede interpretarse como una 
búsqueda de cercanía, antes bien, “(Montaigne) $)^{2}$ Precisa de un lugar lejano donde situarse, desde el cual poder mirarse y mirar a sus contemporáneos. Quiere liberar su yo de las ataduras de un nosotros del que se avergüenza" (Navarro 278). El ensayista, así visto, se siente un actor de primer orden, con posibilidades reales de intervenir y transformar el contexto solo con el poder de sus palabras, aun cuando no se haya trazado un programa político, social o jurídico al momento de empezar a escribir. "(Montaigne) renegando de su presente, del aquí y del ahora de donde él mismo ha surgido, realiza la gran hazaña: mirar la propia mirada, hacer que dentro de sí el otro se encuentre con el otro (...) El yo se sitúa en el exterior y se libra del nosotros" (Navarro 283). En estricto sentido, la nota esencial del ensayo es la indiscutible fe que el autor tiene en su singularidad, gestada en un profundo conocimiento de sí mismo que, a su vez, se ha ido acrisolando a través de los años en el reconocimiento público ${ }^{3}$ que el ensayista, como intelectual, ha obtenido; y como afirma Bourdieu, "[el intelectual] se afirma (...) como el defensor de unos principios universales que no son más que el producto de la universalización de los principios específicos de su propio universo" (198). De esta manera, aunque quien habla pretende ser modesto y renuncia a ser tenido como ejemplo, pone el centro de gravitación de lo que escribe en su propia jactancia.

No en vano, los primeros brotes de ensayo en América Latina se gestaron en el puño de las celebridades de la época: Simón Bolívar, Andrés Bello y José Martí, entre otros, partícipes en la formación de la idea de una nación latinoamericana, segmentada territorialmente, pero identificada con valores, ideas y principios comunes. Con todo, la construcción de esta idea de nación joven, postcolonial, merced a las necesidades de adquisición de un estatus político que

${ }^{2}$ En esta cita, tanto como en la siguiente, Jesús Navarro caracteriza la obra ensayística de Montaigne a partir de su uso recurrente de juegos de miradas para revelar la actitud del autor francés frente a la realidad que le circundaba; en el entendido de que Montaigne es un paradigma vigente en el género, todo lo que Navarro dice sobre él puede aplicarse perfectamente, como se verá, al escritor de ensayos en general.

${ }^{3}$ Los grandes ensayistas, a lo largo y ancho del mundo, y muy especialmente en América Latina, se dieron a conocer en sus territorios, antes que por sus textos literarios, por la realización de labores gubernamentales; varios de ellos, incluso, llegaron a ser presidentes de sus propios países. 
sirviera como escudo para repeler los procesos de reconquista emprendidos por la decadente corona española en el S. XIX, terminó sufriendo los rigores de ser un producto de la inmediatez, del corto plazo. La identidad de cada país, tanto como la latinoamericana, termina por convertirse en motivo de ensayo porque, a pesar de que para la primera veintena del S. XX ya se encuentran constituidas y delimitadas territorialmente, las naciones no han podido establecer a conciencia cuáles son esas características que las asemejan, y cuáles las que las diferencian, de sus vecinas continentales. Es por este motivo que se empieza a cavilar con respecto al tema de la identidad nacional generando un corpus textual sobre el que afirma Irlemar Chiampi:

No encontramos en la reflexión norteamericana, ni en la brasileña, la misma vehemencia, e incluso obsesión con que los hispanoamericanos han sentido la necesidad de definir su cultura en el contexto occidental, de identificarse ante las diversas formas de colonización, de crear un sentido y un método de conocimiento para su realidad histórica. (121)

La tradición del ensayo identitario se nutre de los aportes de diversos autores $^{4}$ que intentan aproximarse a la realidad de su propio territorio desde

${ }^{4}$ Puede decirse que el ensayo identitario latinoamericano es inaugurado en México en 1794 cuando Fray Servando Teresa de Mier desafía la hegemonía española con un sermón donde indigeniza el más sagrado dogma de la época, la aparición de la Virgen María en el Tepeyac. La aparente contradicción entre la figura religiosa de Fray Servando y su sermón blasfemo evidencia la naturaleza autofigurativa del ensayo. Otro aporte relevante es la dualidad civilización-barbarie introducida por Sarmiento en Facundo (1845), obra en la que caracteriza al argentino decimonónico, amén criticar a los representantes de la masa americanista, bárbara, que se ha tomado el poder, dejando de lado la herencia europea, civilizada, que los colonizadores trajeron consigo; sin embargo, su propósito principal es llegar hasta la médula de la nacionalidad argentina para decir que la naciente república ya tiene sus propios conflictos y que, aunque reivindica su derecho a la independencia, puede ser tan civilizada como la colonizadora. En las antípodas de esta representación del argentino se encuentra Martínez Estrada: en su Radiografía de la Pampa (1933) formula una propuesta política que se vale de la identidad nacional para vincular al pueblo con su propia ideología, condena el eurocentrismo de Sarmiento y muestra un argentino comprometido con un futuro socialista. Poco después, Octavio Paz describirá la nacionalidad mexicana en El laberinto de la soledad (1950) desde distintos ámbitos: la marcada tendencia a preferir lo extranjero sobre lo nacional; su búsqueda de un lugar para establecerse, encontrando solo desarraigo en el interregno; sus ambages con respecto a la figura de la muerte, entre otros. La 
categorías universales que, rechazando la influencia española, visibilicen a sus naciones como repúblicas independientes. Siguiendo a Weinberg “(...) con la consolidación de la prosa de ideas a partir del romanticismo, y sobre todo del modernismo, y su rápida difusión a través de la prensa periódica se genera un clima propicio al ensayo y a la génesis de la figura contemporánea del intelectual" (155). Como es previsible, las categorías antedichas son halladas por los autores en la cultura francesa mas encuentran verdadero asidero en el contexto amplio del modernismo.

La escritura ensayística latinoamericana es, si se quiere, una manifiestación del proceso de (re)ubicación de América Latina en el orden mundial y la manera como, tras la reorganización de los centros de poder ${ }^{5}$, el modernismo se implanta en el continente cuando ya se encuentra en su fase imperialista, lo que trae como consecuencia que "las formaciones sociales latinoamericanas [se conviertan] en sociedades neocoloniales, semicoloniales o dependientes" (Pérus 47). Dicho de otra manera, el ensayo de identidad nacional, para el caso específico de las antiguas colonias españolas, tiende a convertirse en depositario de las ideologías de los vencedores en la contienda de la modernidad y no en un constructo autónomo del pensamiento continental: los ensayistas tendían a reflexionar sobre los valores reivindicados por las revoluciones modernas, la tensión entre capitalismo y socialismo y el reconocimiento de tales asuntos dentro de su territorio.

Una cuestión adicional debe considerarse en la transición entre los S. XIX y XX, la implantación del modernismo en América Latina y el ingreso de esta a la economía mundial en calidad de proveedora de materias primas para los países industrializados: a pesar de que el proceso se vivió de maneras distintas en el

crítica se articula con el juego de miradas propuesto por Montaigne del que se ha hecho mención: para Paz mirar desde afuera al mexicano es mirarse a sí mismo, sin estar ahí, pero con la vergüenza propia del que sí está. La lista de obras vinculadas con los procesos de figuración de la identidad nacional y continental podría completarse con otros textos: Las catilinarias (c. 1882) de Montalvo, Siete ensayos de interpretación de la realidad peruana (1928) de Mariátegui y el Contrapunteo cubano del tabaco y el azúcar (1940) de Ortiz, entre otros.

${ }^{5}$ Especialmente tras la entronización de los Estados Unidos como nueva hegemonía hemisférica tras la derrota a España sobre sus últimas colonias de ultramar. 
continente, "El resultado común fue el surgimiento de nuevos modos de producir $\mathrm{y}$ un dinamismo que se transmitió a la sociedad y, sobre todo, a las ciudades del subcontinente" (Altamirano 13). Al interior de cada país, tal circunstancia creó modelos a escala de lo que ocurría en el orden mundial: grandes centros urbanos, cosmopolitas y consumistas frente a diminutos poblados, difícilmente comunicados, sin acceso a la educación y con problemas de abastecimiento de productos básicos. Las situaciones de desigualdad social surgidas por esta causa perviven hasta la actualidad y son claves para definir la producción ensayística continental en razón a que los intelectuales, todos ellos urbanitas, lograron permearse de la cultura de las metrópolis, y recrearlos desde su propia visión del mundo, pero no lograron verterlos completamente a su entorno nacional; como afirma Rama:

Estuvo el modernismo al servicio de los pueblos en la medida en que comprendió la necesidad de apropiarse del instrumental, las formas y los recursos literarios de la literatura creada al calor del universo económico europeo, y fracasó en la medida en que su deslumbramiento ante la nueva manufactura le condenó, y solo parcialmente, muy parcialmente, a la actitud servil imitativa $[\ldots](124-125)$

La independencia intelectual de América Latina aún es objeto de cuestionamientos de todo tipo, mas no puede discutirse el impacto que el ensayo de identidad ha tenido en el desarrollo de escuelas de pensamiento político, sociológico y filosófico al interior de los territorios de cada país, aun cuando su representatividad de la nación sea relativa y que se orienten a la creación de lo que Gramsci denomina "intelectuales orgánicos", aquellos que asimilan la ideología intelectual tradicional con mayor rapidez en aras de perpetuar la hegemonía del grupo político dentro del que ellos mismos se circunscriben (2830). No es casualidad que la producción de textos de identidad nacional, al menos en el caso de América Latina, esté salpicada de referencias extra-nacionales, amén 
de que se contextualice dentro del discurso de quienes detentan, o aspiran a detentar, el poder.

Otro tema debe tenerse presente dentro del modernismo en América Latina: una de sus consecuencias directas, la acumulación de riquezas como valor imperante, trajo consigo la separación definitiva entre lo moralmente viable y lo económicamente conveniente. La sociedad latinoamericana, en términos generales, se decantó por el modelo capitalista y aunque en muchos de sus países surgieron importantes escuelas de pensamiento socialista, para el momento de su arribo ya la propiedad privada imperaba en el continente y las implicaciones humanas de adquirirla y conservarla se convirtieron en un tema de reflexión constante para los ensayistas. El trabajo literario, asumido como postura ideológica representativa de las relaciones sociales reales o posibles (Vidal 17), termina por definir la postura de los intelectuales con respecto a este proceso: en parte compelidos por sus afinidades políticas, algunos asumieron el concepto capitalismo como sinónimo de decadencia moral; así lo afirma Fernández Retamar "[el capitalismo] requería para su florecimiento, entre otros hechos, del inmisericorde pillaje del resto del planeta (aún no maduro para acceder a $s u$ propio capitalismo), a fin de hacer posible en beneficio de una parte de los europeos la acumulación originaria de capital" (119). Empero, no solo los pensadores socialistas formularon este tipo de reparos, muchos "capitalistas" o "indiferentes" hicieron ingentes esfuerzos por puntualizar las equivocaciones del sistema.

Ahora, tras el amplio despliegue autoral y las consideraciones históricas e ideológicas hechas, cabe preguntar, ¿cómo se justifica el hablar sobre el ensayo identitario en la época poscolonial, sobre todo cuando América Latina está viviendo, probablemente a la fuerza, los rigores de la posmodernidad?, ¿de qué manera mirar el nacionalismo cuando se sabe, que solo resulta políticamente crucial en la lucha contra la opresión y que, en otro contexto, no es garantía absoluta de identidad (Spivak 188)?, ¿para qué volver sobre la figura del intelectual, particularmente si la obra de este ya no se encuentra vigente? Es 
importante reconocer, en primer lugar, que aunque se puede hablar, con razón, de un período poscolonial, para el caso de Latinoamérica, muchas de las condiciones del modernismo todavía subsisten con todo rigor, como apunta Said:

Incluso en un amplio número de países del tercer mundo, el clamoroso antagonismo existente entre los poderes del status quo del Estado nacional $\mathrm{y}$ las poblaciones menos favorecidas aprisionadas dentro, pero sin representación o totalmente discriminadas por él, le ofrece al intelectual una oportunidad real para oponerse a la marcha hacia adelante de los vencedores. (53)

En este sentido, pensar desde lo expuesto por el intelectual, particularmente si este ha intentado aproximarse a ese núcleo desde el que se puede concertar la voluntad popular en aras de alcanzar fines superiores, es impostergable. Además, teniendo en cuenta que dentro del estado actual de cosas la supervivencia de los seres se encuentra, al menos simbólicamente, garantizada, corresponde tornar al intelectual para "plantear cuestiones de liberación política y críticas del liderazgo, presentar alternativas que a menudo se ven marginadas o rechazadas como irrelevantes para la batalla principal que se tiene entre manos" (Said 55), en otras palabras, para buscar que los libertadores de hoy no se conviertan en los opresores de mañana.

Por otro lado, aun cuando las cuestiones sobre ciudadanía tienden en la actualidad a ser más o menos fijas, se precisa de una conciencia nacional, pero no de esa nación como ente homogeneizante e impositivo, sino de la nación como construcción colectiva, plural y estable que, reconociendo las diferencias de sus integrantes pueda servir como escudo para repeler los embates aculturadores del neocolonialismo. En este sentido, el ensayo identitario cobra importancia por cuanto obra como informante nativo entre nativos: puede que haya distancia entre quien provee la información y quien la lee, pero este último tendrá elementos suficientes para nutrir su propia percepción de aquello que recibe del primero. 
Valga entonces, por toda justificación al presente texto, el hecho de que la discusión sobre la identidad Latinoamericana se encuentra vigente en todos y cada uno de sus países y que resulta impostergable retener los productos que se han logrado en la reflexión sobre el ser nacional, como mínimos deseables en la búsqueda de la independencia intelectual. Para el caso específico de Colombia, como se empieza a explicar a continuación, tales productos se han buscado a partir de una muestra: la región de Antioquia y su ensayista Luis López de Mesa, procurando mostrar cómo las consecuencias del modernismo se reflejan en la práctica del ensayo identitario.

Colombia no ha sido ajena al ensayo identitario, sin embargo, ha lugar admitir que tal proceso se encuentra apenas en una fase embrionaria; hay señeras aproximaciones en los trabajos de diversos escritores ${ }^{6}$, mas solo Germán Arciniegas y William Ospina han convertido la interpretación del ser nacional y continental en estandarte de su trabajo escritural. Por otra parte, resulta bastante peculiar el hecho de que varios de los otros autores que incursionaron en el género no llegaran a una obra totalizante; hay aproximaciones en Armando Solano, que en Melancolía de la raza indígena (1929) pretende reivindicar la posición del indio en el desarrollo del concepto de nación colombiana; en Cayetano Betancur, que en Sociología de las virtudes y los vicios (1942) hace una comparación irónica de las idiosincrasias antioqueña y bogotana o en Fernando González, que en Los negroides (1936) afirma que el colombiano tiene "complejo de hijo de

${ }^{6}$ La pregunta por la identidad colombiana puede remontarse, históricamente, hasta el Memorial de agravios (1809) de Camilo Torres, las proclamas sediciosas de Antonio Nariño o a los textos que Simón Bolívar escribió en transcurso del proceso independentista; la dicotomía españolcriollo es el germen del ser nacional. En consonancia con esto, tras la independencia, humanistas reconocidos como Miguel Antonio Caro, José María Samper y Rafael Uribe Uribe dedican parte de su producción textual a discurrir en torno al problema de la construcción de una nación colombiana. La ensayística del S. XIX en Colombia se desarrolla, sin mayor reparo, desde la escritura política; la del S. XX, por otro lado, sin apartarse del análisis político, muestra una marcada tendencia a reflexionar desde lo autofigurativo; no es aleatorio que los trabajos de Téllez, Gómez Dávila, Sanín Cano, Otto de Greif, Volkening y Zalamea, entre otros, hayan sido recibidos, a la vez, como las propuestas humanísticas que pretendían ser, pero también como piezas literarias con un valor trascendente al tenor del texto. 
puta", se siente el producto de sucesivos mestizajes vergonzosos, signados por la violencia sexual. Frente a este panorama, es claro que una obra capital, al estilo de Facundo o El laberinto de la soledad, se encuentra lejos de ser escrita.

La principal causa de tal vacío en Colombia puede ubicarse en lo que Rama denomina el "impacto modernizador": la fragmentación de sus regiones, y por ende de sus tendencias culturales, impidió que la tradición y la identidad pudieran resguardarse y adaptarse a nuevas circunstancias, tras el modernismo (74-75). La primera derivación de esto es que las diferencias políticas entre colombianos se convirtieron en luchas intestinas que terminaron por postrar el proceso de construcción de nación. Siguiendo a Sommer: “(...) interminables guerras civiles (...) y las dramáticas barreras geográficas, le proporcionaron a Colombia la nada envidiable distinción de ser prácticamente el único país latinoamericano que no logró algún tipo de consolidación nacional durante el siglo XIX" (232). Esta cuestión puede ampliarse, incluso, hasta el S. XX porque la violencia partidista fue causante directa del surgimiento de las guerrillas en todo el territorio y, por ende, del estancamiento en el que se sumieron todas las regiones del país que se encontraban en la periferia, lejos del poder central o del cerrado triángulo de crecimiento cuyos vértices se fijaron en Bogotá, Cali y Medellín. El colombiano, así visto, es colombiano porque comparte el territorio y obedece al mismo poder; mas si se tratara de definir aquellos factores que lo identifican con los otros, más allá del fanatismo frente a la selección de fútbol y una percepción generalizada sobre la corrupción en el poder, el colombiano anunciaría que no tiene nada que lo asemeje a aquellos de sus coterráneos que se encuentran más allá de las fronteras regionales.

Puede sumarse, a lo anterior, que el tratamiento académico del ensayo identitario se ha centrado, casi exclusivamente, en su valor discursivo ${ }^{7}$, y muy poco en su valía literaria; en este sentido afirma Liliana Weinberg: “(...) se ha

${ }^{7}$ En el entendido de que, como se puede encontrar en Van Dijk, constituyen la ideología de los nuevos grupos hegemónicos en el contexto latinoamericano y, por ende, una representación social directa de su influencia en los ámbitos social, jurídico y político. 
prestado -como es por otra parte natural - una mucho mayor atención a los temas tratados por el ensayo latinoamericano que a los aportes hechos por los ensayistas latinoamericanos a la reflexión sobre el ensayo propiamente dicho y al peculiar modo de interpretación de esos temas" (155). Colombia se destaca por ubicar, bajo el rótulo de "ensayo", las obras de agentes de las más disímiles disciplinas. Tal denominación es intrascendente para los propósitos de este género que, en últimas, puede ser estudiado desde cualquier perspectiva; no obstante, en la divulgación de cada una de las obras se termina privilegiando el contenido sobre la forma, convirtiéndolas en objetos aptos solo para iniciados que dominen las disciplinas desde las que argumente el texto.

Ahora, si en el vasto territorio de Colombia existen dificultades para determinar con claridad meridiana qué es ser colombiano, la pregunta sobre el regional "ser antioqueño", tampoco ha recibido una contestación satisfactoria en los doscientos años de independencia del territorio. Antioquia es una representación en miniatura de lo que, al menos topográficamente, es Colombia: valles, playas, páramos y montañas. Ese sinécdoque que hace la región del país, ideológicamente, se repite: Antioquia ha albergado a liberales, conservadores, fascistas, comunistas, católicos, masones, segregacionistas e integracionistas. Podría pensarse que, en una región tan variopinta, establecer factores identitarios sería una causa perdida ${ }^{8}$, sin embargo, si hay algo de lo que sí puede preciarse el antioqueño es por ser el grupo más visceral a la hora de defender todo lo relativo a sus manifestaciones humanas; de esta manera, el punto de partida para hablar de la identidad antioqueña, en perspectiva frente al país, es la de su profunda convicción de ser única, distinta de las demás identidades regionales de Colombia.

En este escenario aparece Luis López de Mesa: la región antioqueña, con sus poblaciones geográfica o políticamente fragmentadas, siempre convencida de

${ }^{8}$ Reconociendo que este texto busca problematizar la identidad antioqueña desde los rasgos que, sobre ella, se proponen en el corpus ensayístico analizado; no se trata aquí de analizar tal identidad, o la colombiana de la que hace parte, desde el esencialismo que propone el estadonación sino, más bien, desde esas caraterísticas que realzan la litéraritté de estos ensayos. 
su diferencia. Nacido en Donmatías en 1884, este médico de la Universidad Nacional de Colombia, especialista en psiquiatría y psicología de Harvard, se desempeñó como docente en universitario y como ministro de educación y de relaciones exteriores. Sus sus obras más conocidas son: Civilización contemporánea (1926), La tragedia de Nilse (novela, 1928), Biografia de Gloria Etzel (novela, 1929), Introducción a la historia de la cultura en Colombia (1930), De cómo se ha formado la nación colombiana (1934), Disertación sociológica (1939), Nosotros y la Esfinge (1947) y Escrutinio sociológico de la historia colombiana (1956), entre otros. Pocos nombres resuenan tanto aún, en Antioquia, como el suyo: médico, literato, político, crítico social, antropólogo empírico, sociólogo aficionado, sus credenciales son solo comparables con las de los "humanistas" del S. XIX. Es tal su ascendiente sobre el imaginario cultural de la región que su nombre es referencia obligada para hablar sobre ella, su idiosincrasia y sus expresiones sociopolíticas más relevantes.

Es de notar, sin embargo, que el antioqueño viene siendo, por así decirlo, una pieza prescindible del panteón nacional aun cuando haya sido la quintaesencia del "hombre público". Las causas que podrían adjudicarse a este olvido son diversas, no obstante, una de las más plausibles es que se le ha calificado como "fascista" por sus teorías sobre la eugenesia y consecuentes propuestas para el "mejoramiento" de la raza'. Otra posible causa es que López de Mesa fue invisibilizándose paulatinamente en sus últimos años de vida por dedicarse a analizar y criticar a la sociedad antioqueña, olvidando sus vínculos con resto del país ${ }^{10}$. Por último cabe agregar que López de Mesa no creó "textos mayores": solo escribió dos novelas, nunca incursionó en la poesía y cuando

\footnotetext{
${ }^{9}$ No son pocos los discursos del autor en los que se mostró partidario de evitar que los "blancos" colombianos se mezclaran con indígenas o con afrodescendientes y de estimular la inmigración al territorio nacional de europeos, especialmente alemanes y austríacos. López de Mesa, sin embargo, no es el primer humanista que ensaya sobre tales cuestiones: ya José Ingenieros lo había hecho, a su manera, en El hombre mediocre (1913), José Vasconcelos hablaría de ella en La raza cósmica (1925) y Fernando Ortiz en Los negros brujos (1973), solo por poner algunos ejemplos. Como salta a la vista, es un tema que amerita un tratamiento a fondo en un texto posterior.

10 Que, como se verá más adelante, eran fuertes teniendo en cuenta que fue uno de los primeros autores en dedicarse a describir, comprensivamente, al pueblo colombiano.
} 
abrribó a lo literario, tal vez ni siquiera él mismo pensaba hacerlo pues sus ensayos, a pesar de su erudición, no dejaban de ser autofigurativos, lo que les restaba responsabilidad y compromiso autoral ${ }^{11}$. Súmese a esto último que gran parte de su obra se desarrolló en ejercicio labores políticas, razón por la cual no logró descollar en un ámbito menos perecedero, en términos de reconocimiento, que el de la administración pública.

Con todo, la pervivencia de los textos en el momento actual da buena cuenta de su relevancia dentro de las letras colombianas. De este vasto trabajo, una colección de ensayos denominada Nosotros, recopilada por Sergio Arroyave Maya y publicada en 2000, es particularmente útil para hablar de la identidad regional en perspectiva nacional. La obra, compuesta por un corpus de treinta y siete ensayos, describe la personalidad del antioqueño desde los más diversos puntos de vista: su forma de hablar, su actitud frente a los negocios, sus éxitos y fracasos en las humanidades, sus relaciones familiares y sus vínculos con los nacientes medios de comunicación ${ }^{12}$, entre otros. Las apreciaciones vertidas en ellos tienen un tono más bien agrio y su mira apunta a comunicar cierta percepción distópica frente al futuro de la región, teniendo como base el avasallador proceso de industrialización y mercantilización que su cultura vive desde principios del S. XX.

Dentro de las peculiaridades de los textos, la más evidente es que el autor, en ningún momento, utiliza nombres propios para referirse a nada ni a nadie: para hablar de Fernando González prefiere hacer mención de sus visitas a "La Margarita", la finca del célebre escritor; a Rodrigo Arenas Betancur lo reconoce por los aspectos, positivos y negativos, que la crítica de arte ha hecho de sus obras; es tan escrupuloso en estos asuntos que ni siquiera usa gentilicios: "antioqueño" es escaso, "medellinense" no existe y para referirse a los habitantes

${ }^{11}$ En este orden de ideas, se hace particularmente evidente la condición de "género menor" que tiene el ensayo: mientras el lector puede tolerar que se le cuente una mentira completa en la narrativa, se rehúsa a que le cuenten verdades a medias, como puede ocurrir en el ensayo.

${ }^{12}$ Los ensayos que se reúnen en Nosotros fueron escritos en tiempo previo a la muerte de López de Mesa, en 1963, época en la que la radio y la televisión apenas empezaban a masificarse en Colombia. 
de la localidad prefiere el uso del término "aburraesita"13. Otra característica de Nosotros es que López de Mesa, al igual que muchos otros ensayistas, prefiere la comodidad de la autofiguración a la afirmación lapidaria y definitiva, en términos de Gómez Martínez “[...] problematiza un concepto (un supuesto axiológico), no con el propósito de significar en el sentido externo de definir [...], sino con el objetivo de incitar, inspirar a que el lector, en él y para él, signifique" (33); así las cosas, el autor se compromete con lo que piensa al momento de escribir, que no debe variar demasiado de un momento a otro, pero tampoco se preocupa ante la posibilidad de no serse fiel. Finalmente, otra cualidad propia de estos ensayos es que ninguno de ellos se dedica, a fondo, a hablar de temas políticos: el autor prefiere disimular sus vínculos liberales y plantear sus apreciaciones desde una mirada neutral, desapasionada, incluyente.

El primer reconocimiento que hace López de Mesa a Antioquia en sus textos, es a la región como parte de Colombia. No es un error, sobre esta base, interpretar a De cómo se ha formado la nación colombiana como un prólogo remoto a los ensayos de Nosotros. En la primera obra, López de Mesa hace una caracterización a profundidad del país ${ }^{14}$ dividiéndolo por regiones y observando sus manifestaciones culturales, su topografía, la personalidad de sus habitantes y sus personajes celebres. La estructura observada con respecto a Antioquia es la misma, salvo que incluye en el análisis a aquellas entidades que otrora hicieran parte de "Antioquia la grande", los departamentos de Caldas, Quindío y Risaralda. Es de resaltar que la inclusión se hace tratando de enfatizar en el área andina del territorio, sin hablar de las regiones fronterizas con el Chocó y la costa Atlántica, o de Urabá, por entrar estas en las consideraciones sobre las costas en general. Desde la propia descripción, el autor problematiza la situación antioqueña: "arriscadas alturas de pobre vegetación, laderas de vertiginosa pendiente,

${ }^{13}$ Un arcaísmo que hace referencia a la época en la que el río Medellín, que recorre la ciudad y sus municipios vecinos de sur a norte, se conocía como río Aburrá y que sería mucho más acertado de usar en el momento actual, cuando los límites entre las distintas cabeceras urbanas se han desdibujado completamente.

${ }^{14}$ Valga agregar, echando mano de su rica prosa para introducir datos estadísticos y estimaciones numéricas de discutible exactitud. 
verdaderos paredones a veces, que del fondo de los ríos torturados por las rocas trepan sin dar asilo a ningún animal doméstico ni cultivo aprovechable” (94), afirmación de la que se vale para justificar el carácter negociante y recursivo, amén de utilitario y charlatán, del antioqueño a quien compara, constantemente, con el pueblo judío por sus reconocidas competencias en materia mercantil “¿Ni qué otra razón creó en el alma judeo-israelita su cosmopolitismo y sus dotes de traficante que la angustia territorial y económica en que les colocó el mundo? (96)". Empero, estas habilidades mercantiles son, al propio tiempo, motivo principal de su pérdida de valores y progresiva metalización:

Al occidente colombiano ensombrece un poco hoy día la orientación contemporánea hacia una civilización económica, hedonista y sobre todo enamorada del buen éxito fulminante, del triunfo a veces como realización de la personalidad, y del triunfo como obtención de las comodidades que “sensualicen" la vida [...] parece enamorarse más de la riqueza pecuniaria que del espíritu. (105)

El antioqueño, para López de Mesa, sufre de un "avispamiento ruinoso": la posibilidad de crecer económicamente hasta límites insospechados con una marcada discapacidad para reconocer qué límites éticos o morales está transgrediendo. Esta apreciación se robustece con muestras de esas estrategias en las que se apoya el antioqueño para sacar mayor ganancia en todos sus emprendimientos: en Nosotros el ensayo "Lecticinios", enderezado a hacer una denuncia social sobre los malos manejos que, para la época, se dan a la leche en Antioquia, acaba por hacer una cruda radiografía de la realidad de todas las industrias de la región:

[...] si fabricamos alcohol desinfectante, lo dejamos de grado inferior a su debida eficacia; si agua de colonia, nos queda simple; si loción "Old 
Spice”, nos resulta pachulina; si Whisky hacemos, o seudo vino o seudo champaña, ¡Dios nos asista!; si versos pergeñamos, su adjetivación es pobre y sus imágenes manidas o incongruentes; si pintura, composición y colorido son pueriles; si música, sonsonete; si novela, cháchara; si luz eléctrica, un apagón cada rato... inmadurez general, en suma y desorden, exceptuando con patriótico orgullo, señeras unidades en todos los géneros. $(119-120)$

Como puede evidenciarse, lo que en principio no tiene mayores propósitos que hablar sobre la cuestionable rectitud mercantil de los antioqueños, termina por convertirse en un manifiesto sobre su identidad y la manera de relacionarse con los demás miembros de su grupo social. Esta aseveración es contrastada magistralmente cuando habla sobre los gustos del antioqueño para trabar amistad: "es muy demócrata en sus relaciones sociales y da amplia preferencia a las circunstancias morales e intelectuales de sus presuntos allegados" (98). De esta manera, el antioqueño es identificado por el autor como un hábil relacionista público, que sabe con quién tratar para no ser mal visto, mientras que, en su vida privada, es ambicioso y superficial.

Ahora, mirando específicamente lo planteado en Nosotros, es posible complementar lo antes dicho cuando en el ensayo "Psicograma de la gente común" establece que los niños, a quienes llama "rapazuelos" tienen "débiles la memoria conceptual y ética, la atención y la síntesis, con lo cual crecen adictos a la mera sensualidad y el irresponsable lucro" (41). Dicho de otra manera, ese mal que los padres adquieren de manera cultural, merced a la geografía hostil del departamento, termina por convertirse en un mal congénito en su posteridad; la alteración de la moralidad, así vista, se convierte en la justa consecuencia de la ambición desmedida del antioqueño, cuestión más dramática, si se quiere, cuando habla de la "Familia en colapso": "De aquel esposo que entregaba íntegro su jornal o sueldo a la diligente esposa (...) al que hoy rehúye hacerlo (...) con vicios en el hombre, desgreño moral en la mujer e hijos moralmente expósitos" 
(64). La ambición del "aburraesita" lo vuelve mezquino y lo sustrae, incluso, del cumplimiento de sus más elementales obligaciones para con su familia y la sociedad: "Dígalo si no, su tendencia irrefrenable a la evasión, a la fuga de su propia intimidad, ora embriagándose con cuanto puede, marihuana o alcohol, juegos de fullería o bailes de racamandaca, y su agresividad homicida a flor de piel. Dígalo su imprevisión de lo futuro o su monda y lironda ahistoricidad” (60). En síntesis, desde el punto de vista moral, el antioqueño no sale muy bien librado de la pluma de López de Mesa, de hecho, señalar una "decadencia moral” en los ensayos de Nosotros sería impreciso: el autor deplora el comportamiento de sus coterráneos, y lo reprocha desde todo punto de vista, en la medida en que se ha apartado de su condición de ser trascendente para convertirse en una máquina de acumulación de riqueza sin mayor humanidad que su propia anatomía. Valga aquí anotar que, aun cuando López de Mesa no se incluye de manera expresa en este grupo, tampoco hace ningún esfuerzo por marcar distancia con respecto a él, es decir, como observador de tales circunstancias en su contexto territorial, revela una mirada crítica al lector pero se siente incapaz de escapar de su propia realidad; en pocas palabras, siente esa vergüenza de la que se habló al principio de este artículo. Esta afirmación puede refrendarse con la reflexión final de "Cavilaciones":

Como pienso que la escuela pública y la radiodifusión patriótica harían mucho bien, máximo bien quizás, enseñando suasoria y agradablemente, óiganlo sin eufemismos que nuestro querido terruño ya no es el solar del patriciado ejemplar de la república que fue antes, porque ya sus hijos no son ejemplares, y que es imposible, metafísicamente imposible, una Antioquia grande con antioqueños moralmente chiquitos. $\mathrm{Y}$ todos enseñen al unísono e infatigables que ser hombre auténtico gana más dinero, gana más honores y aun más placeres, que la malicia total del mundo. (90-91) 
La remisión aquí a la figura de hombre público de López de Mesa es inevitable, no de otra manera podría aceptarse pacíficamente el hecho de que, sin caer en la contradicción, hable bien y mal, al mismo tiempo, sobre la situación de Antioquia. La percepción distópica se edulcora, como en cualquier discurso político, con la esperanza de un mañana promisorio.

Se ha dado prelación al tema de la decadencia moral del antioqueño porque, para el autor, es la causa de todos sus males y, como se verá en las líneas siguientes, el tema se convierte en punta de lanza para atacar todos los otros flancos de la identidad regional. Baste, en aras de fundamentar esta afirmación, la referencia que en los ensayos "Fealdad de la vestimenta varonil" y "El traje femenino" hace a la presentación personal de los "aburraesitas". Por un lado, las mujeres, aunque no siguen a rajatabla la moda extranjera que "alzó faldas y bajó escotes, hasta el straples y el bikini, y trae a las mujeres a medio cubrir aunque ataviadas de lujo" (49-50), poco a poco se van dejando permear de ella; de otro lado, los hombres, prefieren la economía a la presentación apropiada dejando en el camino su propia identidad en aras de adoptar un "vestido común universal de americana o saco corto" (48). En el caso de las mujeres se evidencia la manera como el autor amplía su óptica y, de la misma manera que alaba las telas producidas por Fabricato y Coltejer (48), enfatiza en la falta de creatividad de los diseñadores y confeccionistas pues, luego de hacer un largo recorrido por las distintas prendas de vestir que se usan en la región, llega a una conclusión lapidaria: "Y como dato importante, en fin, ninguna invención vernácula, ninguna originalidad" (50). A modo de epígrafe sobre este punto, y atendiendo a una observación hecha por su mujer ${ }^{15}$, López de Mesa afirma en "El andar defectuoso" que las aburraesitas caminan con piernas débiles o demasiadas caderas, lo cual les resta elegancia, y como estrategia para corregir esta imperfección sugiere la formación en glamour de las jovencitas de clase alta para

\footnotetext{
${ }^{15}$ Quien aparece, constantemente, a lo largo del texto, como la voz de la razón y el punto de vista más autorizado para hablar sin tapujos sobre la idiosincrasia antioqueña.
} 
que, por simple efecto de la moda, un andar distinguido se vuelva característico de todas las mujeres de la región.

Otro de los contextos en los que se refleja el declive moral del antioqueño, para el autor, se encuentra en el habla. López de Mesa se declara ferviente admirador del habla popular de la región, mas no deja de reconocer su barbarismo. De esta forma, critica en igual medida el voseo, la ensordecedora entonación, la ese casi española, la supresión de consonantes como la de intervocálica o la pe precedente y la confusión de la efe con la jota, sin olvidar los usos correctos de la elle y la equis. "Pobreza fonológica creciente y frustración melódica que reclaman a borbotones algún remedio lectivo, del hogar, por supuesto, de la normal, sin duda, de la radiodifusión certeramente" (38). En consonancia con lo anterior se encuentra el ensayo "Envilecimiento del habla" que, a pesar de no ser más que una parrafada en contra de las palabras soeces que están haciendo carrera en el vocabulario de los jóvenes y, a renglón seguido, una prédica respecto a cómo remediar la situación, resulta atractivo merced al inventario de eufemismos de los que echa mano el autor para decir cuáles son estas palabras:

[...] el oprobioso vizcaíno en ajo; el impúdico derivado del latino fódere que desaloja con su ruda $\mathrm{j}$ al discreto "molestar"; la vitanda palabreja de Cambronne que maridada al verbo ir, y aún peor, mancha más el labio que la dice que el torturado oído que la padece denigrante y rehez por excelencia es la que designa látigo en segunda instancia, y se aplica como insulto; y hasta alabanciosa de bravuconería o matonismo, la feísima con que se denomina al cerdo padre [...]. (56)

Siguiendo el orden de ideas anterior, no podía faltar entre las consideraciones de Nosotros, un acápite dedicado a la manifiesta propensión del antioqueño por el uso de circunloquios para hablar de sexo y, más aún, para generar hilaridad entre sus coterráneos. López de Mesa relaciona tales conductas 
con culturas de bajísima calaña que desplazan la erudición por la rudeza de discusiones pedestres, frívolas, motivadas, en muchas ocasiones, por el ánimo de lucro de quienes las sostienen. En "Radio-enmienda" cuestiona el hecho de que tales costumbres empiecen a hacer carrera en la sociedad antioqueña y que la radio, primer medio de comunicación masivo conocido en la región, en lugar de vetarlas de sus emisiones, las incentive a través de locutores sin mayor pudor. De este modo, se manifiesta en contra del

[...] dicharacho de doble sentido, deshonesto el recóndito, sobre todo coprolálico y pornolálico, que decimos con más bella voz, sicalíptico, aunque no muy castizamente. Ello es que de tal venero de impudencia enmascarada cobran su mayor fortuna nuestros graciosos de turno en las radios populacheras, y será difícil destetar a ésta de aliciente pecuniario y a los otros de sus freudianas deformaciones. $(130-131)$

Nuevamente el factor monetario surge como responsable directo de la pérdida de cultura en Antioquia y, en el caso específico de la radiodifusión, en un mecanismo para la perpetuación de paradigmas que debían haberse erradicado de la cultura regional desde que se empezaron a establecer sus centros urbanos, especialmente el Valle de Aburrá. El estancamiento en el modelo antiguo es más que evidente: el antioqueño puede haber jubilado a sus mulas, pero eso no quiere decir que no las quiera seguir arreando con el exacto vocabulario con que lo harían sus ancestros.

Otro aspecto clave para hablar de identidad regional, según la interpretación de López de Mesa se encuentra, sin lugar a dudas, en la cultura. Esta es mirada, por él, no sólo desde el punto de vista de las "manifestaciones culturales", entendiendo por tales las letras y las artes sino, además, desde el propio comportamiento social de las personas que habitan en Antioquia. Ambos contextos se convierten en trasfondo de, prácticamente, todos los ensayos incluidos en Nosotros y merecen un tratamiento especial. Sobre el 
comportamiento social, el autor es lapidario en afirmar que hay un "retroceso cultural de nuestra gente, ya que no sólo analfabetismo literal se advierte ahora en ella, sino -aplicando abusivamente el término - analfabetismo laboral muy grande, y analfabetismo moral, peligrosísimo" (45), en virtud de eso, el antioqueño se desentiende de los procesos de formación ciudadana y cívica, de sus deberes democráticos e, incluso, de hacerse a una ideología propia. Las causas de tales descuidos se resumen en una sencilla frase "los afanes del negocio en mientes" (46), una vez más se observa cómo la identidad metalizada del antioqueño mina sus posibilidades de hacerse mejor ser humano. El tema del comportamiento social es retomado en "La dieta consuetudinaria" en términos de paradoja para hacer referencia a los hábitos alimenticios que se van adoptando en la época, especialmente entre las jóvenes de clases bajas: cediendo a la tentación de la vanidad, estas prefieren vestir bien a comer bien, lo que coadyuva en un lento proceso de desmejora de la raza. La vanidad es un puntal que López de Mesa no desarrolla demasiado, pero que en la interpretación sistemática del planteamiento discursivo de Nosotros puede verse tanto como una consecuencia del deterioro moral como de la entronización del mercantilismo.

El autor toma en varios momentos la exploración antioqueña de las artes y las letras. El primer aspecto lo desarrolla en tres contextos: bellas artes, escultura y arquitectura y dibujo y artes pictóricas, aunque los tematiza imbricándolos unos a otros. En sus meditaciones, López de Mesa no busca fijar las razones por las que el antioqueño sea un arquitecto mediocre ${ }^{16} y$, por ende, poco reconocido, o que los artistas que mayores aportes hicieron al arte regional (Francisco Antonio Cano, Pedro Nel Gómez, Hugo Martínez González y Ricardo Rendón) se hubieran quedado sin reemplazo; lo que López de Mesa cuestiona es que en épocas más aciagas para el ejercicio de las artes, se hubiera logrado mucho más que en el S. XX, cuando estas ya eran apreciadas en debida forma. Este argumento se hace más fuerte con respecto a poetas y novelistas, solo que, en su

\footnotetext{
${ }^{16}$ La obra que más presume para la época, la Catedral Metropolitana de Medellín, le resulta corpulenta y oscura.
} 
caso, el autor sí se atreve a formular la causa de la decadencia y falta de protagonismo que estos viven en su momento:

[...] una novelística admirable a principios de esta centuria, cuando éramos más pobres, más aislados del mundo y más desprovistos de recursos culturales, que luego sucedió un eclipse de ella por toda una generación, y que al reaparecer en medio de comodidades económicas, sociales, lectivas, no se reanudó el triunfo sino que el meridiano del prestigio pasa hoy por otras regiones $[\ldots](164)$

Ni siquiera Fernando González, con todo y la amistad que lo une a él, se salva de la crítica: a López de Mesa sus novelas le resultan cautivadoras, vivas, artísticas, tanto como incongruentes, desordenadas e innecesariamente exhibicionistas (172).

A modo de conclusión general, la paradoja que plantean los ensayos recogidos en Nosotros de Luis López de Mesa resulta evidente: a pesar de su título, tales textos, como los de Montaigne, buscan ubicar al individuo afuera de la colectividad para demostrar la vergüenza que esta le genera. Para el caso específico del antioqueño, tal vergüenza procede de la manera como Antioquia se ha insertado dentro del modernismo y ha pasado de ser, cultural y socialmente hablando, una promisoria tierra decimonónica a una caótica zona que, a pesar de estar más conectada con el mundo, ha cambiado lo humano por lo mundano. El autor sabe que será escuchado, sus años se trabajo en la administración pública y la academia le brindan reconocimiento suficiente para legitimar lo que dice; es por esto que, aunque sus ensayos estén dentro de lo autofigurativo, el autor no se molesta en afirmar que no pretende ser ejemplar y llega a dar a sus textos un tono de sermón similar al de los políticos de plaza pública. 
La premisa principal de López de Mesa para ensayar sobre la identidad de la región antioqueña y sus habitantes, es poner en evidencia el hecho de que, tras la inserción tardía en el modernismo de la que se habló antes, se adoptó la acumulación de riqueza como valor social imperante haciendo que un simple ingenio mercantil deviniera en rampante metalización. Para abordar el tema, el autor se vale de categorías universales y un discurso grandilocuente, como el intelectual modélico de Bourdieu, pero parece olvidar que su postura enunciativa es la del habitante de una urbe que está creciendo de espaldas a las zonas rurales que se encuentran dentro de la misma región. Esta oposición ciudad-poblado, de entrada, refleja lo que Rama criticara sobre los intelectuales de la época: hay apropiación de la cultura foránea, pero no hay comprensión de lo local, lo cual está condenando a este corpus ensayístico a no ser verdaderamente representativo de esa personalidad que pretende refejar, extendiendo la desigualdad social a la manera que anuncia Altamirano.

Más allá de la pertenencia de López de Mesa a la ciudad letrada, con las consecuentes desigualdades que ello engendra, se encuentra la similitud que establece (como lo hicieran Vidal, Pérus o Fernández Retamar, solo por mencionar algunos) entre capitalismo y decadencia moral: el autor es enfático en señalar que la causa común a todos los males que padece Antioquia se encuentra en el ánimo de lucro que se ha extendido a todas las prácticas sociales, áreas de conocimiento y sectores de la población. El autor afirma que el antioqueño padece de un "avispamiento ruinoso", es decir, de una predisposición al aprovechamiento de la ignorancia o la falta de astucia ajena que resulta moralmente reprochable. Para demostrar este efecto, se vale de ejemplos de todo tipo, desde prácticas comerciales aparentemente inocentes, como poner partes de agua a la leche para que rinda más; pasando por la renuencia de los padres de familia a compartir el salario con sus cónyuges, incumpliendo su deber de proveedores; hasta caer en prácticas socialmente irresponsables como renunciar a la educación, o a sus deberes cívicos, para atender sus negocios. Resulta relevante, en este aspecto que López de Mesa, a pesar de tener afinidades con el liberalismo colombiano, en 
ninguno de sus textos se afirma políticamente, menos como socialista. Tal ambigüedad es el mejor señuelo para atraer lectores en una región donde ser liberal es lo mismo que ser comunista y ser comunista es lo mismo que ser "enemigo personal" de Jesucristo; el autor es consciente de que bordea límites controversiales y que traspasarlos podría redundar en pérdida de público, por eso ofrece la alternativa política de decir que lo que necesita la región es educarse y que tal educación debe ser fomentada a todo nivel, en lugar de atacar la cuestión afirmando que hay que controlar el afán de lucro y la acumulación de riquezas.

No hay en el contexto poscolonial una razón de peso para hablar de nacionalismo, o al menos a la manera como este es comprendido dentro del concepto de Estado-nación; como bien lo afirma Spivak, tal concepto solo sirve para luchar contra la opresión. Sin embargo, es claro que el retorno a los ensayos identitarios, en general y a los de Luis López de Mesa, en particular, se legitima en la medida en que ellos proponen una lectura nativa de la cultura de la región: el arte, la arquitectura, la literatura, la filosofía y los medios de comunicación masiva, entre otros, se encuentran plenamente representados dentro de los textos y, aun cuando no salgan bien librados en la crítica feroz que les hace el autor, se interpretan como parte integral del ser de Antioquia. Es claro que construir una identidad regional resulta mucho más complejo que textualizar la cultura, pero es un punto de apoyo para resistir los embates de lo que Rama denomina el "impacto modernizador", aquello que hace que la fragmentación territorial redunde en fragmentación ideológica; es posible admitir, en gracia de discusión, que resulta anacrónico retomar tal concepto cuando ya se está hablando de posmodernidad, mas tal anacronismo se contrasta con la plena vigencia en la que se encuentra el neocolonialismo a nivel mundial. La identidad, más allá de entenderse como un factor homogeneizante o un requisito del nacionalismo, es la manera de asirse lo que se ha construido dentro de la autonomía cultural del pueblo.

Antioquia, como sinécdoque topográfico de Colombia, es una muestra de la que se puede echar mano para hablar de identidad y los ensayos incluidos en Nosotros lo constatan: López de Mesa se empeña en mostrar, hasta el detalle, 
cómo es la región (o al menos el Valle de Aburrá) para establecer que sus valores adquiridos, aun siendo cuestionables, son el producto de su acontecer histórico y de la posibilidad de sus habitantes de determinarse sin obedecer a las imposiciones de un colonizador. Desde una perspectiva contenidista del ensayo, resulta obvio, textos de este estilo no tendrían ningún tipo de valor porque fueron producidos en otra época y para otro tipo de sociedad; desde el análisis del ensayo como objeto literario, su vigencia es imperecedera, pues a la representación de factores notables de un pueblo, en un momento determinado, le suma la capacidad del autor para mostrar críticamente cómo se ve ese pueblo desde afuera.

\section{Bibliografía}

Altamirano, Carlos y Jorge Myers, eds. Historia de los intelectuales en América Latina. I. La ciudad letrada, de la conquista al modernismo. Buenos Aires: Katz Editores, 2008. Impreso.

---. Historia de los intelectuales en América Latina. II. Los avatares de la "ciudad letrada" en el siglo XX. Buenos Aires: Katz Editores, 2010. Impreso.

Betancur, Cayetano. Sociología de la autenticidad y la simulación. Medellín: Ediciones Autores Antioqueños, 1988. Print.

Bourdieu, Pierre. Las reglas del arte. Génesis y estructura del campo literario. Barcelona: Anagrama, 1995. Impreso.

Chiampi, Irlemar. El realismo maravilloso. Caracas: Monte Ávila, 1983. Impreso. Fernández Retamar, Roberto. Todo Calibán. Buenos Aires: Clacso Libros, 2004. Impreso.

Giraldo, Efrén. Negroides, simuladores, melancólicos. El ser nacional en el ensayo colombiano del siglo xx. Medellín: Fondo Editorial Universidad Eafit, 2012. Impreso. 
Gómez Martínez, José Luis. Teoría del ensayo. México D.F.: UNAM, 1992. Impreso.

González, Fernando. Los negroides: (ensayo sobre La Gran Colombia). Medellín: Editorial Bedout, 1970. Impreso.

Gramsci, Antonio. La formación de los intelectuales. México D.F.: Grijalbo, 1967. Impreso,

López de Mesa, Luis. De cómo se ha formado la nación colombiana. Medellín: Editorial Bedout, 1970. Impreso.

---. Nosotros, seguida de El nueve de abril. Arroyave Maya, comp. Medellín: Imprenta Departamental de Antioquia, 2000. Impreso.

Martínez Estrada, Ezequiel. Radiografía de la pampa. México: Unesco, 1993. Impreso.

Navarro Reyes, Jesús. "Mirar desde otro: Montaigne y el relativismo cultural". Themata. No. 27 (2001): 277 - 284. Impreso.

Paz, Octavio. El laberinto de la soledad. México D.F: Fondo de Cultura Económica, 1983. Impreso.

Pérus, Françoise. Literatura y sociedad en América Latina: el Modernismo. La Habana: Casa de las Américas, 1976. Impreso.

Proyecto filosofía en español. Fr. Servando de Mier. Apuntes del sermon de 12 de diciembre de 1794. 2008. Web. 3 Ene. 2014.

Rama, Ángel. Transculturación narrativa en América Latina. México D.F.: Siglo XXI Editores, 1982. Impreso.

---. Rubén Darío y el Modernismo. Caracas: Alfadil Ediciones, 1985. Impreso.

Sarmiento, Domingo Faustino. Facundo o civilización y barbarie en las pampas argentinas. Buenos Aires: elaleph.com, 2000. 18 nov. 2012.

Said, Edward. Representaciones del intelectual. Barcelona: Paidós,1994. Impreso.

Solano, Armando. La melancolía de la raza indígena. Bogotá: Librería colombiana, 1929. Impreso. 
Sommer, Doris. Ficciones Fundacionales. Las novelas nacionales de América Latina. México D.F: Fondo de Cultura Económica, 2004. Impreso.

Spivak, Gayatri C. A Critique of Postcolonial Reason. Toward a History of the Vanishing Present. Cambridge: Harvard University Press, 1999. Impreso.

Vidal, Hernán. Literatura hispanoamericana e ideología liberal: surgimiento y crisis. (Una problemática sobre la dependencia en torno a la narrativa del boom). Buenos Aires: Ediciones Hispamérica, 1976. Impreso.

Weinberg, Liliana. "Ensayo, cultura e identidad latinoamericana", en: Zea y Magallón, eds. Latinoamérica, economía y política. México: Instituto Panamericano de Geografía - Fondo de Cultura Económica, 1999. Impreso. 